\title{
BMJ Open Qualitative analysis of young adult ENDS users' expectations and experiences
}

\author{
Janet Hoek, ${ }^{1}$ Johannes Thrul, $^{2}$ Pamela Ling ${ }^{3}$
}

To cite: Hoek J, Thrul J, Ling P. Qualitative analysis of young adult ENDS users' expectations and experiences. BMJ Open 2017;7:e014990. doi:10.1136/bmjopen-2016014990

- Prepublication history and additional material is available. To view please visit the journal (http://dx.doi.org/ 10.1136/bmjopen-2016014990).

Received 31 October 2016 Revised 23 January 2017 Accepted 8 February 2017

CrossMark

${ }^{1}$ Department of Marketing, University of Otago, Dunedin, New Zealand

${ }^{2}$ Center for Tobacco Control Research and Education, University of California San Francisco,

San Francisco, California, USA

${ }^{3}$ Center for Tobacco Control Research and Education and Division of General Internal Medicine, University of California San Francisco, San Francisco, California, USA

Correspondence to Professor Janet Hoek; janet.hoek@otago.ac.nz

\section{ABSTRACT}

Objectives: Despite extensive research into the determinants of electronic nicotine delivery system (ENDS) uptake, few studies have examined the psychosocial benefits ENDS users seek and experience. Using a consumer ritual framework, we explored how ENDS users recreated or replaced smoking practices, and considered implications for smoking cessation.

Design: In-depth interviews; data analysed using thematic analysis.

Setting: Dunedin, New Zealand.

Participants: 16 young adult ENDS users (age $\mathrm{M}=21.4, \mathrm{SD}=1.9 ;$;4\% female).

Results: Participants reported using different ENDS to achieve varying outcomes. Some used 'cigalikes' to recreate a physically and visually similar experience to smoking; they privileged device appearance over nicotine delivery. In contrast, others used personally crafted mods to develop new rituals that differentiated them from smokers and showcased their technical expertise. Irrespective of the device they used, several former smokers and dual users of cigarettes and ENDS experienced strong nostalgia for smoking attributes, particularly the elemental appeal of fire and the finiteness of a cigarette. Non-smoking participants used ENDS to maintain social connections with their peers.

Conclusions: Participants used ENDS to construct rituals that recreated or replaced smoking attributes, and that varied in the emphasis given to device appearance, nicotine delivery, and social performance. Identifying how ENDS users create new rituals and the components they privilege within these could help promote full transition from smoking to ENDS and identify those at greatest risk of dual use or relapse to cigarette smoking.

\section{INTRODUCTION}

Global initiatives to reduce smoking prevalence have stimulated interest in electronic nicotine delivery systems (ENDS), which reduce smokers' exposure to toxicants in smoked tobacco and may provide safer alternatives for those who have repeatedly tried but failed to quit. ${ }^{1-5}$ Yet despite these

\section{Strengths and limitations of this study}

- Use of in-depth qualitative interviews elicited rich and complex data that offer important new insights into electronic nicotine delivery system (ENDS) and smoked tobacco attributes that facilitate or deter transition from smoking.

- Variations in ENDS users' expectations, experiences and ritual development may help identify groups where relapse to smoking is more likely and assist healthcare providers to develop tailored support for these groups.

- Our study is deliberately exploratory in nature, thus patterns and experiences of ENDS use presented require testing with a larger sample before they can be generalised.

potentially appealing attributes, concerns exist over ENDS' wider population effects, particularly given brand proliferation, extensive product marketing and rapid uptake among young people. ${ }^{6-12}$ Debate continues over whether ENDS offer a gateway to smoked tobacco, ${ }^{13} 14$ renormalise smoking, ${ }^{6}{ }^{15}$ or reduce cessation among smokers. $^{16} 17$

ENDS have evolved rapidly from cigarette replicas, or 'cigalikes', which look similar to traditional smoked cigarettes and are more standardised, to second generation options including highly patterned and sleekly designed vape pens. ${ }^{18} 19$ Third generation devices, or 'mods', are typically larger, more technically complex and sophisticated. These options offer users many personalising opportunities by allowing them to select from multiple flavour options, determine the nicotine content of their e-liquid, and customise the aerosol produced to create diverse consumption experiences. ${ }^{20} 21$ Yet while studies have documented ENDS use among existing smokers, ${ }^{22}$ identified determinants of uptake ${ }^{23-25}$ and examined reported smoking cessation outcomes, ${ }^{26-28}$ few have explored the psychosocial benefits ENDS users seek. Addressing these questions 
could provide important insights into how ENDS use evolves, and the role (if any) that smoked tobacco continues to play.

Consumer ritual theory presents a novel framework to explore how ENDS users construct or recreate practices that replace smoking. Rituals comprise specific artefacts, scripted behaviours, roles, and audiences that support uniquely personal practices while also featuring common actions that support social connections. ${ }^{29-31}$ In the context of ENDS, these ritual components include the specific device (artefact), how these are used (scripts and roles) and the usage contexts (audiences). For example, mods users may construct their artefact, develop 'tricks' or scripts that illustrate their skill in creating and controlling vapour, and perform these tricks in social settings where they share or compete with peers (roles and audiences). Replacing cigarettes with ENDS while retaining familiar roles and scripts may reaffirm smokers' past experiences while simultaneously supporting behaviour change and creating new social capital. ${ }^{32-34}$

ENDS' diversity may help users retain, reinforce or replace elements of their smoker (or non-smoker) identity. For example, new rituals could involve a simple transition from one artefact (cigarette) to another (ENDS), or construction of new non-smoker identities that reject smoking artefacts and scripts. We currently know little about how ENDS users recreate former smoking rituals or whether they develop new behaviours to distance themselves from smoking. To address these questions, we explored how young adults used ENDS to develop rituals that communicate their personal and social identities.

\section{METHODS}

\section{Sample and recruitment}

We recruited participants within New Zealand, a country that has not approved nicotine-delivering ENDS for use as smoking cessation treatments, ${ }^{35}$ though individuals may import e-liquid containing nicotine for personal use. Since smoking prevalence peaks among young adults and e-cigarette use has increased rapidly among adolescents, we expected to see greater ENDS use and more divergent practices among young people aged 1825 , and thus sampled from this group. ${ }^{36} 37$

We used community advertising, social media and fliers distributed through outlets selling ENDS to recruit participants. We collected preliminary information on potential participants' smoking and ENDS use, and used these details to recruit people whose usage patterns varied. Interviewing occurred in Dunedin, a provincial city with a high young adult population ${ }^{38}$ and home of the first retail vaporium in New Zealand. In total, we interviewed 16 participants during 2014 and 2015; all had used ENDS within the past 30 days, typically on multiple occasions. All participants received a $\$ 30$ gift voucher in recognition of any costs they incurred while assisting with the research.

\section{Data collection}

We used in-depth semistructured interviews as this approach allows participants to recall, recount and reflect on their behaviours, and elicits rich and complex data. ${ }^{39-41} \mathrm{JH}$ and $\mathrm{PL}$ conducted four interviews jointly and $\mathrm{JH}$ conducted the remaining 12 interviews.

The interviews examined participants' use of smoked tobacco, their ENDS awareness, and their trial, uptake and experiences of using ENDS (see online supplementary file 1). As the interviews progressed, we made minor modifications to the protocol to incorporate new ideas for exploration with subsequent participants. Interviews lasted between 40 and $75 \mathrm{~min}$, and continued until data saturation had occurred (the final two interviews did not elicit new idea elements).

\section{Ethical considerations and review}

Participants received a copy of the information sheet prior to each interview; they were also advised orally of their rights before they provided written consent.

\section{Data analysis}

We recorded interviews with participants' consent and transcribed these verbatim. JH and PL independently interpreted four transcripts; we used an inductive approach to identify idea elements, map the relationships between these, and form tentative themes, which we reviewed, discussed and agreed before $\mathrm{JH}$ coded remaining transcripts. $\mathrm{JH}$ reviewed the data using consumer ritual theory as an overarching analytical framework; we used a thematic analysis approach ${ }^{42}$ and examined metaphors associated with each ritual component, the practices participants reported, and their overall experiences of using ENDS. We assigned participants a pseudonym, which we use when attributing quotes.

\section{RESULTS}

The sample comprised nine men and seven women (age $\mathrm{M}=21.4, \mathrm{SD}=1.9$ ); most first smoked in their late teens and began using an e-cigarette in their early 20s; initiation for both products typically occurred in social settings (see table 1 ).

Participants reported divergent experiences and their ENDS rituals existed along a continuum. At one end, participants reported using cigalikes to replicate the appearance and experience of smoking. They altered only their artefact (device) but retained other ritual elements to preserve their smoker identity and maintain behavioural connections with their audience (social group), many of whom still smoked. At the other end, participants used ENDS that differed from cigarettes in appearance and function. The bespoke devices they crafted differentiated them from smokers and their rituals showcased these devices to other technically sophisticated 'hobbyists'. Irrespective of the device they used, several participants missed elements of smoking 
Table 1 Participants' characteristics

\begin{tabular}{|c|c|c|c|c|c|c|c|c|c|c|c|c|}
\hline $\begin{array}{l}\text { Participant } \\
\text { Pseudonym }\end{array}$ & Age & Gender & $\begin{array}{l}\text { Age of first } \\
\text { cigarette }\end{array}$ & $\begin{array}{l}\text { Initiation } \\
\text { setting }\end{array}$ & $\begin{array}{l}\text { Current } \\
\text { smoking }\end{array}$ & $\begin{array}{l}\text { Smoking } \\
\text { Frequency }\end{array}$ & $\begin{array}{l}\text { Age of first } \\
\text { ENDS use }\end{array}$ & $\begin{array}{l}\text { Initiation } \\
\text { settingt }\end{array}$ & $\begin{array}{l}\text { Owned } \\
\text { ENDS } \neq\end{array}$ & $\begin{array}{l}\text { Current } \\
\text { vaping }\end{array}$ & $\begin{array}{l}\text { ENDS } \\
\text { used } \\
\text { (current }^{\star} \text { )§ }\end{array}$ & Nicotine \\
\hline Andy & 22 & $M$ & 17 & Social & Intermittent & $<$ weekly & 21 & Alone & Yes & Stopped & $\begin{array}{l}\text { Cigalike } \\
\text { vape pen* }\end{array}$ & Yes \\
\hline Ben & 20 & $M$ & 17 & Social & Intermittent & $<$ weekly & 19 & Social & No & Intermittent & Mod & Yes \\
\hline Craig & 19 & $M$ & 14 & Social & $\begin{array}{l}\text { Not } \\
\text { smoking }\end{array}$ & & 19 & Social & No & Intermittent & Vape pen & Yes (unsure) \\
\hline Dani & 19 & $\mathrm{~F}$ & 18 & Social & Smoking & 8-10/day & 19 & Alone & Yes & Intermittent & Cigalike & No \\
\hline Edward & 22 & $M$ & 15 & Social & Smoking & $20+/$ day & 21 & Social & No & Intermittent & Vape pen & No (unsure) \\
\hline Freddie & 23 & $M$ & 17 & Personal & Intermittent & 1-2/day & 23 & Alone & Yes & Daily & Mod & Yes \\
\hline Gavin & 23 & $M$ & 14 & Personal & Intermittent & $<$ weekly & 22 & Social & Yes & Daily & $\begin{array}{l}\text { Cigalike } \\
\text { mod* }^{*}\end{array}$ & Yes \\
\hline Hettie & 20 & $\mathrm{~F}$ & 18 & Social & Intermittent & $<$ weekly & 20 & Social & No & Intermittent & $\begin{array}{l}\text { Vape pen } \\
\text { cigalike }^{*}\end{array}$ & No (unsure) \\
\hline Izzy & 20 & $\mathrm{~F}$ & 16 & Social & Intermittent & 2-3 days/week & 20 & Social & Yes & Daily & Cigalike & Yes \\
\hline Jackie & 23 & $\mathrm{~F}$ & 16 & Social & $\begin{array}{l}\text { Not } \\
\text { smoking }\end{array}$ & & 22 & Social & Yes & Daily & $\begin{array}{l}\text { Cigalike } \\
\text { mod* }^{*}\end{array}$ & Yes \\
\hline Kevin & 24 & $M$ & 21 & Social & Intermittent & Once a week & 24 & Social & No & Intermittent & Vape pen & Yes (unsure) \\
\hline Lee & 22 & M & 18 & Social & $\begin{array}{l}\text { Not } \\
\text { smoking }\end{array}$ & & 22 & Social & Yes & Daily & $\begin{array}{l}\text { Cigalike } \\
\text { vape pen } \\
\text { mod }^{*}\end{array}$ & Yes \\
\hline Mona & 22 & $\mathrm{~F}$ & 14 & Social & Intermittent & Once a week & 21 & Social & Yes & Daily & $\begin{array}{l}\text { Cigalike } \\
\text { vape pen* }\end{array}$ & $\begin{array}{l}\text { Yes } \\
\text { no }\end{array}$ \\
\hline Neil & 20 & $M$ & 18 & Social & $\begin{array}{l}\text { Very } \\
\text { infrequent }\end{array}$ & 1-2/year & 19 & Social & Yes & Daily & Mod & No \\
\hline Olivia & 19 & $\mathrm{~F}$ & 18 & Social & $\begin{array}{l}\text { Very } \\
\text { infrequent }\end{array}$ & Rarely & 19 & Social & No & Intermittent & $\begin{array}{l}\text { Cigalike } \\
\text { vape pen* }\end{array}$ & Yes \\
\hline Petra & 25 & $\mathrm{~F}$ & 18 & Social & Daily & $\begin{array}{l}\text { 3-5/day; } 10-20 \\
\text { when drinking }\end{array}$ & 20 & Social & Yes & Daily & Cigalike & Unsure \\
\hline
\end{tabular}


and felt nostalgic for those attributes, or found ENDS did not deliver the same nicotine 'hit', or offer the counter-cultural, rebellious, connotations they valued. Non-smokers who used ENDS had little interest in simulating smoking or differentiating themselves from smokers, and used ENDS to maintain social connections within their networks.

\section{Replication}

Participants seeking to replicate smoking typically used cigalikes and found retaining the appearance of smoking more important than accessing nicotine. Izzy explained: "You usually find e-cigarettes are big vape pens like about this big [uses hands to show size]...with tanks and everything, but this one feels like a cigarette so it really helped with the process of quitting smoking 'cos it still feels like you're smoking a cigarette" (Izzy). Physical similarities enabled easy substitution of one artefact for another, thus maintaining valued ritual elements; as Izzy described: "what I've done is just transferred from tobacco to e-cigarettes and I've kept all the same sort've habits and that's why it was so easy to just drop cigarettes...because I've kept my habits of smoking" (Izzy). These participants emphasised retaining tangible ritual components; Mona noted: "with the e-cigarettes again it's the fact of actually still smoking and so still physically doing something so it doesn't...it almost doesn't feel like I've completely quit" (Mona).

By recreating the aesthetic appeal of cigarette sticks, cigalikes enabled participants to maintain near-identical behaviours and thus the same scripts, roles and audiences. Gavin, who had used cigalikes before switching to a mod, observed: "...it seems to me like cigarettes [are] ...not just a chemical addiction but [have] a lot of other psychological factors built into them, like the look of them, the satisfaction of the cylindrical...you know, the geometry of them" (Gavin). The physical familiarity of cigalikes retained anticipatory attributes that participants had valued in former smoking rituals.

Participants' efforts to retain smoking microbehaviours may explain why past quit attempts using pharmacological support had failed. While replacing nicotine, NRT (nicotine replacement therapies) required them to relinquish smoking rituals, such as handling cigarettes, which some used to manage anxiety. One participant had observed her peers trying to quit and explained the importance of ancillary actions: "I know a lot of people when they quit, they try to replace it with something and...they don't know what to do with their hands... [cigalikes keep] that routine of, you know, getting up and going out with a coffee and having a smoke, you could still do that" (Olivia).

Several cigalike users had tried different ENDS yet returned to cigalikes because the flavours and aesthetics of vape pens and mods did not support the smoking ritual they wanted to recapture. Although motivated to reduce the risks and costs smoking imposed on them, participants wanted an artefact as physically similar to cigarettes as possible. Petra explained: "They [cigalikes] ...they look like a smoke, they feel like a smoke, the only difference is you don't need a lighter and that's about it. Otherwise it just feels like you're holding a normal cigarette and it tastes like a normal cigarette but you've not got all of the ...forty thousand billion chemicals in it... when I had my friend's vaporizer, it just didn't look right and it just didn't feel right... and when I tried it I was like "nah this is definitely not what a smoke-what an e-smoke should taste like' so, no" (Petra).

Although these participants valued their cigalike for its similarity to smoking, others sought to differentiate themselves from smokers and so used visually distinctive third generation ENDS, or mods.

\section{Ostentatious differentiation}

While mods users distanced themselves from smoking by altering every observable component of their former smoking ritual, they wanted to retain the sensation of inhaling, access to nicotine, and occupying their hands. Lee explained: "that's the thing about the vaporisers...I mean...you can get your nicotine. You can also get... that habit... of consumption, of inhalation, that feels very similar and...still gives you something to fiddle with your hands so...yeah, kind of covers all the bases for people who do smoke" (Lee).

Rather than simulate smoking rituals, these participants created their own artefacts, developed new scripts (or tricks) and roles to showcase their possessions. They cultivated a social persona of 'pro-sumer' (ie, production by consumers). Many described intensely personal acts of creation: they made coils, manipulated the voltage delivered, produced unique flavours, and tailored the vapour their device produced. Participants viewed themselves as 'techies' or 'hobbyists', as Freddie stated: "I'm quite a big techie in terms of um, things coming out and [I'm] always interested in um...all the new releases and...the enormous...hobby culture behind it across the world um, that I'd never known of before" (Freddie). The creativity required to build mods attracted potential users, as Andy explained: "I thought it was interesting that it could be customized so much if you knew what you were doing (Andy) and elevated "hobbyists" into artists: [ people] have turned [building mods] into a hobby...there's a lot of customizations that you can do. There's a lot of...very artistic things people are doing with them, making these enormous contraptions" (Freddie). Mods provided these participants with opportunities to star in their own performances and conferred on them a social standing they would not have achieved through smoking.

Participants embarked on a continuous improvement quest to enhance their artefacts; Lee explained: "it's... that creative side of it and that ritualistic side...especially if you do [make] your own, building your own [mods]... you can customise it and build it and...do different things with it-make it better" (Lee). Creating bespoke devices provided participants with personal satisfaction; Neil outlined his ongoing motivation: "I do it purely just 
for enjoyment of the whole cloud thing and the whole flavour of it...just like a hobbyist side of things, so you have to build the little coils yourself-it's a lot more customizable and...you can kind've personalize them to suit what you want to do with them" (Neil). Like Neil, Gavin gained pleasure from crafting the appearance, flavour, and content of his 'cloud': "really advanced users that make up their own juice and stuff um, you can change the ratio of PG [propylene glycol] to VG [vegetable glycerine] to make it more or less, smoky or, like, more or less flavorsome" (Gavin). Controlling their performances brought considerable satisfaction; as Jackie explained, ENDS not only showcased creativity but offered control over what they consumed: "I just like having a greater level of control over essentially what I'm putting into my lungs" (Jackie).

Yet while many participants valued the variety mods offered, even those who had transitioned from smoking to ENDS missed some elements of smoking. The third theme, nostalgic dissatisfaction, explores the importance of attributes unique to smoking.

\section{Nostalgic dissatisfaction}

Participants who had not found ENDS fulfilling missed physical attributes of smoking, or the structure smoking provided, and spoke nostalgically about these experiences. While many participants valued being able to use their ENDS in settings where they could not smoke, others missed the norm of smoking outside and felt they had lost an 'excuse' to take a break. Dani explained this feeling: "like one of the things I like the most about smoking was that I could take some time out of my day 'cos I was so busy... and I didn't kind've have any reason to go and sit outside"” (Dani).

Participants' comments highlighted differences in the sensory experiences ENDS provided. Edward, a vape pen user, recalled the taste and smoke of cigarettes: "The [cigarette] smoke is more...dense and I think it's more...beautiful, it's more fun...I miss the...the taste of the tobacco and the nicotine... and I couldn't be stopped...I still wouldn't quit the tobacco and the nicotine "cos I still would miss it" (Edward). Dani had a similar reaction and saw her cigalike as inferior to smoking: "I can't kind've trick myself into thinking that I'm smoking if I'm inhaling or something and then go [exhale] and this much smoke that you see here is coming out of [exhale]...you know this, this is bullshit, you know. It's much more difficult to try and trick myself into...thinking that it's the real deal" (Dani). Their inability to recreate the sensory and visual experience of smoking created a sense of loss for these participants.

Even mods aficionados like Freddie reflected wistfully on smoking's physical attributes, particularly the speed of nicotine delivery: "the flavour's not exactly the same, it doesn't have the same viscosity as a normal cigarette um, it...the nicotine hit so to speak is a little bit delayed...the combustible one you get the definite... inhale and then...yeah, your brain goes [whoa, whoa, whoa, whoa] ...[laugh]...with all the chemicals and that's instantaneous while this one...it'll hit you slower"(Freddie). Gavin missed retrieving and holding cigarettes: "[cigarettes are] nice...they feel good, you can bend them a little bit but they don't snap and the boxes are so perfect and...really just satisfying to touch and to feel" (Gavin). While some participants either substituted these sensory differences or accepted a reduced experience, others' connections with smoking rituals felt irreplaceable.

Participants also missed the physical changes a cigarette underwent while being consumed. Andy explained: "I think the way the people do use these...is quite different though because um...you just don't have to stop" (Andy). For some, consuming a cigarette was an accepted moment in time that ENDS could not replicate: "it [an ENDS] doesn't get smaller...whereas in a cigarette...like once you finish it you can feel like it's... completed like you relax, like it's something that you've gone through" (Hettie). Ben also valued the mutability of a smoked cigarette, the visual satisfaction of seeing it diminish, and the microbehaviours that were part of his former smoking ritual: "I think there's also a certain amount of satisfaction seeing the size of the cigarette change...that as you inhale more...it gets brighter...it becomes shorter, you can tap it to get rid of the ash, you can...yeah" (Ben). A finite experience offering a clear beginning and ending was essential to these participants' rituals.

Participants also recalled and missed important attributes that symbolised initiation and conclusion, which they associated exclusively with cigarettes. For example, the initial flame was a potent visual metaphor: "Part of the excitement of smoking, I feel, is like the lighter and the fire [laugh]...Whereas an e-cigarette-I can't even remember-do you turn it on-do you-no you don't eh-you just like breathe through it. Um...yeah-it doesn't have fire or anything like that" (Hettie). Perceptions of ENDS as safer than smoking removed important non-conformist and rebellious overtones that some participants valued: "an e-cigarette seems less satisfying than a real cigarette does. 'Cos it seems like alike a carbon copy of it - of the real thing...if someone smokes that instead, it's almost like they're trying to copy someone...with a cigarette" (Hettie). The "carbon copy' lacked authenticity and made ENDS an unsatisfactory replacement for smoking; Dani explained: "E-cigarettes as much as they try, are not the same as regular cigarettes-not, not at all so, you know, going outside with an e-cigarette would be like going outside with no cigarette basically" (Dani).

These participants saw smoking rituals as accomplishments; they 'go through' a defined experience, from retrieving a cigarette to lighting it, to finally extinguishing it. Although other ENDS users developed new initiation and completion rituals, these participants found the loss of fundamental attributes rendered alternative rituals less meaningful. 


\section{Social connectors}

Our sample also included non-smokers whose social networks included smokers and ENDS users. These participants disliked smoking and used ENDS as more palatable and safer alternatives that enabled them to share in group behaviours and avoid feeling isolated when their friends went outside to smoke. As Kevin explained: "the kind of um...social engagement...it's just something to...to do...accompanying some company" (Kevin).

Neil explained the dilemma of engaging in a distasteful ritual or losing status as a connected social group member: "the whole nicotine thing with the whole, like, throat hit and everything...I just find it too harsh and it's not really even enjoyable for me, so I don't see any point in doing that if you can...go out with your friends if they're on a smoke break... and just go hang out... and have the whole social thing with it" (Neil). ENDS provided Neil with a parallel ritual that maintained his social connections; Olivia also valued this attribute. She explained the awkwardness of abstaining from shared rituals: "I think everyone wants to fit in so...if your friend group smokes, like 'cos since all mine do...it's kinda awkward for me when I don't smoke and they all go outside together and I'm like 'oh well, do I stay in by myself?" (Olivia).

These participants used ENDS to create social connections and capital, and demonstrate active audience membership; Olivia noted: "for me it's just more of a social thing 'cos like everyone's out there with something in their hand and then...it's just something I can join in too...like I don't think I'd sit at home by myself with one" (Olivia). Maintaining connections with her peers was more important than the device she used and Olivia did not own an ENDS but rather used whatever device others offered to her.

Craig, another non-smoker, described tricks as a social practice that he and his peers enjoyed: "They [friends] could like fill up a glass with smoke... and then someone else could like breathe it in. Stuff like that and...they did the same thing in a cup and then they, like, tried to make a tornado and stuff like that. Like the-the smoke was a lot cooler" (Craig). Maintaining self-described hobbyist Neil's social standing required him to demonstrate technical expertise through building a mod and developing tricks; his device was his social connection and thus played a more important role in his ritual.

Other participants also reflected on social group interactions and observed that ENDS enabled their nonsmoking friends to participate in rituals formerly the exclusive domain of smokers: "the main thing that my friends really liked about them was just that you could still smoke but it wasn't as addictive because you don't have the nicotine in it, if you were getting nicotine-free liquid, you could still kind've join in on the social aspect of smoking but without actually...smoking" (Mona). Although the physical harshness and social stigma of smoking deterred non-smokers, ENDS' attributes appealed to smokers and non-smokers by supporting shared social rituals.

\section{DISCUSSION}

ENDS use has proliferated among young people, ${ }^{43}$ even where strict product access policies exist. ${ }^{37}$ We probed motivations for ENDS use and identified different practices, where young people used varied artefacts and scripts, and performed distinctive roles to different audiences. Our findings extend earlier studies by identifying complex interactions between device choice (cigalike, vape pen or mod), nicotine delivery, and ritual maintenance or creation. ${ }^{193944} 45$ Consumer ritual theory provides a rich framework for exploring ENDS use as a social practice and explicating users' practices, which privileged different components of rituals. ${ }^{29} 46$ Some participants used cigalikes to perform scripts that rendered them almost indistinct from social group members who smoked while others created entirely new rituals, proclaimed new identities as skilled innovators, and developed tricks and novel scripts they performed to elite user communities. ${ }^{19} 39$ 47-49 Despite their sometimes enthusiastic adoption of new devices, many former smokers missed aspects of smoking and some found ENDS unsatisfying because they lacked authenticity. ${ }^{44}$ Non-smokers placed varying emphasis on their device, which gained meaning by enabling social connections. ${ }^{50}$

Our study has some potential limitations. We sampled purposively to recruit a heterogeneous group with varied behaviours, but focussed on a relatively small sample of young adults. Although most likely to adopt emerging behaviours, this group does not represent all ENDS users, and we acknowledge that other practices may exist. For example, older mods users may privilege effective nicotine delivery over artefact appearance and performances. $^{51} 52$ Exploring ENDS practices among a larger and more diverse sample would further explicate the rituals identified and help explain residual connections to smoking that impede full cessation. Despite these limitations, our findings offer novel and rich insights into the varied expectations and experiences of ENDs users, and provide intriguing new explanations of why full transition from smoking often does not occur.

We extend earlier work by explaining how conditioned cues associated with nicotine delivery reinforce some users while creating aversive reactions in others. ${ }^{53-55}$ Since the appearance of the device may compensate for less efficient (or absent) nicotine delivery, ${ }^{54} 56$ promoting visual similarity and continued access to tactile components of smoking could foster transition from smoking and reduce nicotine dependence among some smokers. ${ }^{56}$ We provide new insights into mods users, who wished to replicate a physiological experience while replacing cues they viewed as stigmatised. ${ }^{54}$ 57-59 Their emphasis on efficient nicotine delivery and ritual performances explains the importance of replacing the psychopharmacological attributes of combustible cigarettes, 
while differentiating the devices themselves. Participants who prioritised elemental attributes such as fire found ENDS unsatisfactory and continued to smoke. Even dedicated hobbyists wistfully recollected the excitement of ignition and completion experienced when extinguishing a cigarette. Although these findings require further analysis with larger and more diverse samples, they may explain why dual use continues, and why smoking relapse remains an important risk. Non-smoking ENDS users prioritised neither nicotine delivery (as they wished to avoid addiction) nor visual similarity. They valued the social aspects of ENDS use; the artefact they used gained value by providing access to desired social audiences.

Despite the extensive attention paid to ENDS uptake and use, most studies have examined usage outcomes rather than users' expectations and experiences. We begin to address this important gap using consumer ritual theory, which explains how users privilege different components of rituals and why even elaborate new rituals may not compensate for attributes unique to smoking. Understanding ENDS users' practices could help tailor the advice given to smokers, identify the most suitable ENDS product for them, and potentially promote full transition from smoking.

Acknowledgements The authors thank the research participants who provided the data reported on in this article.

Contributors $\mathrm{JH}$ conceptualised and designed the project. With PL, she designed the research protocol, collected data and analysed the transcripts. JH led the MS development; JT and PL provided detailed feedback on early iterations of the MS. All authors have seen and approved the final version; $\mathrm{JH}$ is guarantor of the MS.

Funding This research received no specific grant from any funding agency in the public, commercial or not-for-profit sectors.

\section{Competing interests None declared.}

Ethics approval The project was reviewed and approved by a delegated authority from the University of Otago Human Ethics Committee.

Provenance and peer review Not commissioned; externally peer reviewed.

Data sharing statement No additional data are available.

Open Access This is an Open Access article distributed in accordance with the Creative Commons Attribution Non Commercial (CC BY-NC 4.0) license, which permits others to distribute, remix, adapt, build upon this work noncommercially, and license their derivative works on different terms, provided the original work is properly cited and the use is non-commercial. See: http:// creativecommons.org/licenses/by-nc/4.0/

\section{REFERENCES}

1. Benowitz N, Goniewicz M. The regulatory challenge of electronic cigarettes. JAMA 2013;310:685-6.

2. Hajek P, Etter J-F, Benowitz N, et al. Electronic cigarettes: review of use, content, safety, effects on smokers and potential for harm and benefit. Addiction 2014;109:1801-10.

3. Hajek P. Electronic cigarettes have a potential for huge public health benefit. BMC Med 2014;12:225.

4. Goniewicz ML, Knysak J, Gawron M, et al. Levels of selected carcinogens and toxicants in vapour from electronic cigarettes. Tob Control 2014;23:133-9.

5. McNeill A, Munafò M. Reducing harm from tobacco use. $J$ Psychopharmacol 2012;27:13-18.

6. de Andrade M, Hastings G, Angus K. Promotion of electronic cigarettes: tobacco marketing reinvented? BMJ 2013;347:f7473.
7. Chapman S. Should electronic cigarettes be as freely available as tobacco cigarettes? No. BMJ 2013;346:f3840.

8. Grana RA, Ling PM. "Smoking revolution": a content analysis of electronic cigarette retail websites. Am J Prev Med 2014;46:395-403.

9. Emery SL, Vera L, Huang J, et al. Wanna know about vaping? Patterns of message exposure, seeking and sharing information about e-cigarettes across media platforms. Tob Control 2014;23 (Suppl 3):iii17-25.

10. Zhu S-H, Sun JY, Bonnevie E, et al. Four hundred and sixty brands of e-cigarettes and counting: implications for product regulation. Tob Control 2014;23(Suppl 3):iii3-9.

11. Duke JC, Lee YO, Kim AE, et al. Exposure to electronic cigarette television advertisements among youth and young adults. Pediatrics 2014;134:e29-36.

12. Paek H-J, Kim S, Hove T, et al. Reduced harm or another gateway to smoking? Source, message, and information characteristics of e-cigarette videos on YouTube. J Health Commun 2014;19:545-60.

13. Barrington-Trimis JL, Berhane $\mathrm{K}$, Unger JB, et al. The e-cigarette social environment, e-cigarette use, and susceptibility to cigarette smoking. J Adolesc Health 2016;59:75-80.

14. Rennie LJ, Bazillier-Bruneau C, Rouëssé J. Harm reduction or harm introduction? Prevalence and correlates of e-cigarette use among French adolescents. J Adolesc Health 2016;58:440-5.

15. Fairchild AL, Bayer R, Colgrove J. The renormalization of smoking? e-cigarettes and the tobacco "Endgame". N Engl J Med 2014;370:293-5.

16. Lee S, Grana RA, Glantz SA. Electronic cigarette use among Korean adolescents: a cross-sectional study of market penetration, dual use, and relationship to quit attempts and former smoking. $J$ Adolesc Health 2014;54:684-90.

17. Kalkhoran S, Glantz SA. E-cigarettes and smoking cessation in real-world and clinical settings: a systematic review and meta-analysis. Lancet Respir Med 2016;4:116-28.

18. Yingst JM, Veldheer S, Hrabovsky S, et al. Factors associated with electronic cigarette users' device preferences and transition from first generation to advanced generation devices. Nicotine Tob Res 2015;17:1242-6.

19. McQueen A, Tower S, Sumner W. Interviews with "vapers": implications for future research with electronic cigarettes. Nicotine Tob Res 2011;13:860-7.

20. Villanti AC, Richardson A, Vallone DM, et al. Flavored tobacco product use among US young adults. Am J Prev Med 2013;44:388-91.

21. Kong G, Morean ME, Cavallo DA, et al. Reasons for electronic cigarette experimentation and discontinuation among adolescents and young adults. Nicotine Tob Res 2015;17:847-54.

22. Hitchman SC, Brose LS, Brown J, et al. Associations between e-cigarette type, frequency of use, and quitting smoking: findings from a longitudinal online panel survey in Great Britain. Nicotine Tob Res 2015;17:1187-94.

23. Ramo DE, Young-Wolff KC, Prochaska JJ. Prevalence and correlates of electronic-cigarette use in young adults: findings from three studies over five years. Addict Behav 2015;41:142-7.

24. Wackowski OA, Bover Manderski MT, Delnevo CD, et al. Smokers' early e-cigarette experiences, reasons for use, and use intentions. Tob Regul Sci 2016;2:133-45.

25. Lee H-Y, Lin H-C, Seo D-C, et al. Determinants associated with e-cigarette adoption and use intention among college students. Addict Behav 2017;65:102-10.

26. Biener L, Hargraves JL. A longitudinal study of electronic cigarette use in a population-based sample of adult smokers: association with smoking cessation and motivation to quit. Nicotine Tob Res 2015;17:127-33.

27. Bullen $\mathrm{C}$, Howe $\mathrm{C}$, Laugesen $\mathrm{M}$, et al. Electronic cigarettes for smoking cessation: a randomised controlled trial. Lancet 2013;382:1629-37.

28. Grana RA, Popova L, Ling PM. A longitudinal analysis of electronic cigarette use and smoking cessation. JAMA Intern Med 2014;174:812-13.

29. Rook DW. The ritual dimension of consumer behavior. J Consum Res 1985:251-64.

30. Hoek J, Ferguson S, Court E, et al. Qualitative exploration of young adult RYO smokers' practices. Tob Control 2016: doi:10.1136/ tobaccocontrol-2016-053168

31. Poland B, Frohlich K, Haines RJ, et al. The social context of smoking: the next frontier in tobacco control? Tob Control 2006;15:59-63.

32. McVea KL, Miller DL, Creswell JW, et al. How adolescents experience smoking cessation. Qual Health Res 2009;19:580-92.

33. Tombor I, Shahab L, Herbec A, et al. Smoker identity and its potential role in young adults' smoking behavior: a meta-ethnography. Health Psychol 2015;34:992-1003. 
34. Brown S, Kozinets RV, Sherry JF Jr. Teaching old brands new tricks: retro branding and the revival of brand meaning. J Mark 2003;67:19-33.

35. Ministry of Health. Advice on the use of e-cigarettes. Ministry of Health, 2015

36. Ministry of Health. Tobacco use 2012/13: New Zealand health survey. Wellington: Ministry of Health, 2014.

37. White J, Li J, Newcombe R, et al. Tripling use of electronic cigarettes among New Zealand adolescents between 2012 and 2014. J Adolesc Health 2015;56:522-8.

38. Statistics New Zealand. 2013 census QuickStats about a place: Dunedin City, age and sex. Wellington: Statistics New Zealand, 2015.

39. McDonald EA, Ling PM. One of several 'toys' for smoking: young adult experiences with electronic cigarettes in New York City. Tob Control 2015;24:588-93.

40. Hoek J, Hoek-Sims A, Gendall P. A qualitative exploration of young adult smokers' responses to novel tobacco warnings. BMC Public Health 2013;13:609.

41. Hoek J, Maubach N, Stevenson R, et al. Social smokers' management of conflicted identities. Tob Control 2013;22:261-5.

42. Braun V, Clarke V. Using thematic analysis in psychology. Qual Res Psychol 2006;3:77-101.

43. Centers for Disease Control and Prevention. More than a quarter-million youth who had never smoked a cigarette used e-cigarettes in 2013. Atlanta, Georgia: Centers for Disease Control and Prevention, 2014.

44. Rooke C, Cunningham-Burley S, Amos A. Smokers' and ex-smokers' understanding of electronic cigarettes: a qualitative study. Tob Control 2015;25:e60-6.

45. Wadsworth E, Neale J, McNeill A, et al. How and why do smokers start using e-cigarettes? Qualitative study of vapers in London, UK. Int J Environ Res Public Health 2016;13:661.

46. Gainer B. Ritual and relationships: interpersonal influences on shared consumption. J Bus Res 1995;32:253-60.

47. Belk R. Possessions and the extended self. J Consum Res 1988;15:139-68.

48. Cooper M, Harrell MB, Perry CL. Comparing young adults to older adults in e-cigarette perceptions and motivations for use: implications for health communication. Health Educ Res 2016;31:429-38.

49. Measham F, O'Brien K, Turnbull G. "Skittles \& Red Bull is my favourite flavour": e-cigarettes, smoking, vaping and the changing landscape of nicotine consumption amongst British teenagersimplications for the normalisation debate. Drugs Educ Prev Policy 2016;23:224-37.

50. Beverland MB, Farrelly FJ. The quest for authenticity in consumption: consumers' purposive choice of authentic cues to shape experienced outcomes. J Consum Res 2010;36:838-56.

51. Farsalinos KE, Spyrou A, Tsimopoulou K, et al. Nicotine absorption from electronic cigarette use: comparison between first and new-generation devices. Sci Rep 2014;4:4133.

52. St Helen G, Havel C, Dempsey DA, et al. Nicotine delivery, retention and pharmacokinetics from various electronic cigarettes. Addiction 2016;111:535-44.

53. Cooper M, Harrell MB, Perry CL. A qualitative approach to understanding real-world electronic cigarette use: implications for measurement and regulation. Prev Chronic Dis 2016;13:1-9.

54. Dawkins L, Kimber C, Puwanesarasa Y, et al. First-versus second-generation electronic cigarettes: predictors of choice and effects on urge to smoke and withdrawal symptoms. Addiction 2015;110:669-77.

55. Norton KJ, June KM, O'Connor RJ. Initial puffing behaviors and subjective responses differ between an electronic nicotine delivery system and traditional cigarettes. Tob Induc Dis 2014;12:17.

56. Dawkins L, Munafò M, Christoforou G, et al. The effects of e-cigarette visual appearance on craving and withdrawal symptoms in abstinent smokers. Psychol Addict Behav 2016;30:101-5.

57. Greaves L, Oliffe JL, Ponic P, et al. Unclean fathers, responsible men: smoking, stigma and fatherhood. Health Sociol Rev 2010;19:522-33.

58. McCool J, Hoek J, Edwards R, et al. Crossing the smoking divide for young adults: expressions of stigma and identity among smokers and non-smokers. Nicotine Tob Res 2013;15:552-6.

59. Ritchie D, Amos A, Martin C. "But it just has that sort of feel about it, a leper"-stigma, smoke-free legislation and public health. Nicotine Tob Res 2010;12:622-9. 